\title{
Consumo e digestibilidade de nutrientes em novilhos suplementados e terminados em pasto, na seca
}

[Intake and digestibility of nutrients in steers supplemented and finished on pasture in the dry season]

\author{
C.E.S. Baroni ${ }^{1}$, R.P. Lana $^{1,4^{*}}$, A.B. Mancio ${ }^{1}$, B.P.C. Mendonça ${ }^{2}$, M.I. Leão ${ }^{1}$, C.B. Sverzut ${ }^{3}$ \\ ${ }^{1}$ Departamento de Zootecnia - UFV \\ Av. P.H. Rolfs, s/n \\ 36571-000 - Viçosa, MG \\ ${ }^{2}$ Aluno de pós-graduação - DZO-UFV - Viçosa, MG \\ ${ }^{3}$ Faculdade de Engenharia Agrícola - UNICAMP - Campinas, SP \\ ${ }^{4}$ Bolsista do $\mathrm{CNPq}$
}

\begin{abstract}
RESUMO
Avaliaram-se o consumo e a digestibilidade de nutrientes por novilhos Nelore suplementados com elevado teor de proteína na terminação, em pasto, durante a seca. Foram utilizados quatro novilhos com 30 meses e peso médio inicial de $440 \mathrm{~kg}$, distribuídos em quadrado latino 4x4 (quatro níveis de suplementação e quatro períodos de 16 dias). Foram usados quatro piquetes de um hectare de capim Panicum maximum cv. Tanzânia, e os animais receberam: 0 (grupo-controle); 1,$0 ; 2,0 ;$ ou 4,0kg de suplemento/dia. Os suplementos, à exceção do controle, apresentaram níveis decrescentes de proteína bruta (58 a 32\% da matéria seca) e proporções de mistura mineral:ureia:farelos de 10:10:80, 5:5:90 e 2,5:2,5:95 para os respectivos tratamentos. O consumo e a digestibilidade foram determinados com o uso do óxido crômico e FDAi, o delineamento estatístico foi em quadrado latino, e os tratamentos foram avaliados pela análise de regressão. Houve efeito linear crescente sobre o consumo e sobre os coeficientes de digestibilidade da matéria seca, proteína bruta, extrato etéreo e fibra em detergente neutro, e sobre o consumo de nutrientes digestíveis totais. Não houve efeito sobre o consumo de pasto e o consumo e a digestibilidade dos carboidratos não fibrosos. Os suplementos avaliados em geral melhoraram o consumo e a digestibilidade e, consequentemente, o valor nutritivo da dieta de novilhos em terminação sob pastejo, no período da seca.
\end{abstract}

Palavras-chave: bovino de corte, energia, farelo de soja, suplemento, capim-tanzânia

\begin{abstract}
The effects of supplements with high protein content on intake and digestibility were evaluated in Nellore steers finished at pasture during the dry season. Four steers avering 30-month old and initial weight of $440 \mathrm{~kg}$ were distributed in a $4 \times 4$ Latin square (four levels of supplementation and four periods of 16 days). Four paddocks of one hectare containing Panicum maximum $c v$. Tanzania grass were utilized and the animals received 1.0, 2.0, or $4.0 \mathrm{~kg}$ of supplement/day, in addition to a control - mineral mixture. The supplements, except control, presented decreasing levels of crude protein (58 to $32 \%$ in dry matter) and the proportions of mineral mixture:urea:cereal meals were 10:10:80, 5:5:90, and 2.5:2.5:95 for the treatments. The intake and digestibility were determined with the use of chromium oxide and ADFi. The statistical design was Latin square and the treatments were evaluated by regression analysis. There was an increasing linear effect on the intakes and digestibility coefficients of dry matter, crude protein, ether extract, neutral detergent fiber, and intake of total digestible nutrients. There was no effect on the intake of pasture and intake and digestibility of non-fiber carbohydrates. It can be concluded that the evaluated supplements generally improve the intake and digestibility and consequently the nutritive value of the diets of finishing animals on the pasture during the dry season.
\end{abstract}

Keywords: beef cattle, energy, soybean meal, supplement level, Tanzania

Recebido em 18 de dezembro de 2009

Aceito em 31 de março de 2010

*Autor para correspondência (corresponding author)

E-mail: rlana@ufv.br 


\section{INTRODUÇÃO}

A pecuária de corte no Brasil baseia-se na criação de animais em pastagens, e esta é a forma mais simples e de mais baixo custo de alimentação dos ruminantes. Uma tendência dos sistemas de produção de carne nos trópicos é explorar, ao máximo, o potencial da forragem durante o período favorável de crescimento, o que permite bom desempenho animal a baixo custo (Lana, 2005b).

A prática de suplementação alimentar permite ganhos de peso acima dos estabelecidos apenas com a ingestão de pasto. No entanto, a suplementação deve ser usada com cautela, com o objetivo de corrigir os desequilíbrios nutricionais e aumentar o consumo, e permitir a melhor utilização da forragem disponível, pelo aumento da digestibilidade e da eficiência de síntese microbiana (Oliveira et al., 2004; Barbosa et al., 2007). Há necessidade de realizar pesquisas no Brasil com o objetivo de verificar a resposta dos animais ao uso do concentrado e não à formulação de dietas para satisfazer os requisitos nutricionais, levando em consideração a relação custo-benefício da atividade (Lana, 2005a).
O objetivo deste trabalho foi avaliar o efeito da suplementação à base de farelo de soja sobre o consumo e a digestibilidade aparente de nutrientes por novilhos Nelore terminados em pastagem de Panicum maximum cv. Tanzânia, no período da seca.

\section{MATERIAL E MÉTODOS}

O experimento foi realizado na Fazenda Vale do Sonho, localizada no município de AraguaianaMT, cuja coordenada geográfica é $15^{\circ} 8^{\prime} 44^{\prime \prime}$ de latitude Sul e 51 ${ }^{\circ} 52^{\prime} 36^{\prime \prime}$ de longitude Oeste. O clima predominante da região é o tropical quente, com precipitação anual média de $1.480 \mathrm{~mm}$. O trabalho foi desenvolvido durante o período da seca, entre os meses de julho e outubro.

Foram utilizados quatro novilhos da raça Nelore castrados, com médias de idade e peso inicial, respectivamente, de 30 meses e $440 \mathrm{~kg}$, para avaliação do consumo e da digestibilidade aparente total. $\mathrm{O}$ delineamento experimental adotado foi o quadrado latino $4 \times 4$, com quatro níveis de suplementação (Tab. 1) e quatro períodos de 16 dias, sendo os seis últimos dias de cada período destinados à coleta de amostras de pasto, de suplemento e de fezes.

Tabela 1. Composição percentual dos suplementos, com base na matéria natural, utilizados por novilhos Nelore, em terminação, na seca

\begin{tabular}{|c|c|c|c|c|}
\hline \multirow{2}{*}{ Ingrediente $(\%)$} & \multicolumn{4}{|c|}{ Tratamento (kg/animal/dia) } \\
\hline & 0,0 & 1,0 & 2,0 & 4,0 \\
\hline Farelo de milho & - & - & - & 28,6 \\
\hline Farelo de soja & - & 40,8 & 70,2 & 56,7 \\
\hline Ureia/sulfato de amônia & - & 7,1 & 3,6 & 1,8 \\
\hline $\begin{array}{l}\text { Mistura mineral } \\
\text { comercial }\end{array}$ & 100 & - & - & - \\
\hline Sal comum $(\mathrm{NaCl})$ & - & 1,1 & 0,6 & 0,3 \\
\hline Suplemento comercial & - & 51 & 25,6 & 12,7 \\
\hline \multicolumn{5}{|c|}{$\begin{array}{l}\text { Composição da mistura mineral comercial: } \mathrm{Ca}, 6,5 \% ; \mathrm{P}, 6,5 \% ; \mathrm{Na}, 15,8 \% ; \mathrm{Mg}, 0,5 \% ; \mathrm{S}, 1,8 \% ; \mathrm{Mn}, 0,05 \% ; \mathrm{Cu}, 0,1 \% \text {; } \\
\text { Zn, } 0,2 \% \text {; Fe, 0,075\%; I, 0,0075\%; Co, 0,0075\%; Se, 0,001\%; F, 0,1\%; e N, 4,5\%. } \\
\text { Composição do suplemento comercial: PB, 22,5\%; NNP, 2,5\%; P, 1\%; Ca, 1,67\%; Na, 4\%; Mg, 0,3\%; S, 0,45\%; Cu, } \\
0,0075 \% \text {, Co, 0,001\%; Fe, 0,01\%; I, 0,0015\%; Mn, 0,05\%; Se, 0,0001\%; Zn, 0,03\%; palatabilizante, 0,5\%; e } \\
\text { antioxidante, } 0,1 \% \text {. }\end{array}$} \\
\hline
\end{tabular}

A área experimental foi constituída de quatro piquetes de 1 ha cada, cobertos uniformemente com gramínea Panicum maximum cv. Tanzânia, providos de cocho de duplo acesso e um bebedouro de alvenaria central. Foram avaliados suplementos constituídos de milho grão triturado, farelo de soja, ureia, sulfato de amônio, mistura mineral e suplemento comercial (Tab. 1). Os suplementos foram fornecidos diariamente, em comedouro individual, às $8 \mathrm{~h}$, a fim de minimizar a interferência do efeito substitutivo sobre o comportamento de ingestão da forragem (Adams, 
1985). Foram utilizadas quantidades crescentes de suplemento: 0,0 (tratamento-controle); 1,0; 2,0 e 4,0kg/animal/dia (Tab. 2).

No início do experimento, todos os animais foram submetidos ao controle de ecto e endoparasitas e desverminados com vermífugo à base de moxidectina a $1 \%$. No primeiro dia de cada período experimental, foi realizada coleta de forragem para determinação da disponibilidade total de matéria seca/ha. Os cortes foram feitos rente ao solo, colhendo-se toda a forragem em cinco áreas delimitadas por um quadrado metálico de $0,5 \times 0,5 \mathrm{~m}\left(0,25 \mathrm{~m}^{2}\right)$, escolhidos aleatoriamente em cada piquete experimental (McMeniman, 1997).

A amostragem do pasto foi realizada via simulação manual de pastejo, como sugerido por Aroeira (1997), por meio da observação cuidadosa da preferência animal quanto às partes da planta ingerida. Posteriormente à observação, material semelhante em composição botânica e morfológica, arrancado com a mão, simulando o pastejo animal, em todos os piquetes, foi colhido pelo mesmo observador, para evitar discrepâncias entre as coletas.

Tabela 2. Composição bromatológica dos suplementos e da pastagem de Panicum maximum selecionada pelos novilhos, com base na matéria seca

\begin{tabular}{|c|c|c|c|c|}
\hline \multirow{2}{*}{$\begin{array}{l}\text { Item } \\
\text { (\% da MS) }\end{array}$} & \multicolumn{3}{|c|}{ Tratamento (kg/animal/dia) } & \multirow{2}{*}{$\begin{array}{c}P . \text { maximum } \\
\text { (pastejo simulado) }\end{array}$} \\
\hline & 1,0 & 2,0 & 4,0 & \\
\hline $\mathrm{MS}(\%)$ & 91,4 & 94,5 & 95,4 & 50,24 \\
\hline PB & 57,5 & 49,4 & 31,9 & 6,44 \\
\hline PIDN & - & - & - & 1,62 \\
\hline PIDA & - & - & - & 0,92 \\
\hline $\mathrm{EE}$ & 2,9 & 2,3 & 7,2 & 1,52 \\
\hline FDN & 37,5 & 46,3 & 57,5 & 72,05 \\
\hline FDA & 8,7 & 8,9 & 8,7 & 38,40 \\
\hline FDNcp & - & - & - & 68,90 \\
\hline FDAcp & - & - & - & 36,04 \\
\hline FDNi & 3,1 & 1,8 & 2,9 & 37,37 \\
\hline FDAi & 1,5 & 0,9 & 1,5 & 19,96 \\
\hline Celulose & - & - & - & 39,74 \\
\hline Lignina & - & - & - & 7,24 \\
\hline Cinzas & 14,2 & 10,6 & 6,7 & 5,92 \\
\hline CHOT & - & - & - & 86,11 \\
\hline CNF & - & - & - & 17,23 \\
\hline
\end{tabular}

MS: matéria seca; PB: proteína bruta; PIDN: proteína insolúvel em detergente neutro; PIDA: proteína insolúvel em detergente ácido; EE: extrato etéreo; FDN: fibra em detergente neutro; FDA: fibra em detergente ácido; FDNcp: fibra em detergente neutro corrigida para cinzas e proteína; FDAcp: fibra em detergente ácido corrigida para cinzas e proteína; FDNi: fibra em detergente neutro indigestível; FDAi: fibra em detergente ácido indigestível; CHOT: carboidratos totais ((100-(\%PB+\%EE+\%CZ)); CNF: carboidratos não fibrosos (\%CHOT-\%FDNcp).

Todas as amostras colhidas foram armazenadas em sacos plásticos, previamente identificados, congeladas a $-10^{\circ} \mathrm{C}$ e transportadas para o laboratório para determinação das características químico-bromatológicas. As amostras, descongeladas à temperatura ambiente e previamente secas em estufa ventilada a $60 \pm 5^{\circ} \mathrm{C}$, por 72 horas, foram moídas em moinho tipo Wiley, com peneira de $1 \mathrm{~mm}$, e armazenadas em potes de plástico, devidamente identificados.

$\mathrm{O}$ indicador foi fornecimento aos animais entre o terceiro e o $16^{-}$dia experimental, utilizando $17 \mathrm{~g}$ de óxido de cromo $\left(\mathrm{Cr}_{2} \mathrm{O}_{3}\right)$, por dia. $\mathrm{O}$ óxido de cromo foi acondicionado em cartuchos de papel e introduzido por aplicador, via oral, às $13 \mathrm{~h}$. Amostras de fezes foram coletadas às $18,16,14$, 12,10 e 8 horas, respectivamente, do $11^{\mathrm{o}}$ ao $16^{\mathrm{o}}$ dia do período experimental. As fezes, coletadas diretamente no reto dos animais, em quantidades aproximadas de $200 \mathrm{~g}$, foram armazenadas em sacos plásticos, identificados por animal e período e congeladas a $-10^{\circ} \mathrm{C}$. Posteriormente, foram descongeladas à temperatura ambiente, colocadas em pratos de alumínio para présecagem em estufa de ventilação forçada a 
$60 \pm 5^{\circ} \mathrm{C}$, por 72 horas, quando então foram moídas em moinho tipo Wiley, com peneira de $1 \mathrm{~mm}$, e armazenadas como amostras compostas por animal no período, em potes de plástico, devidamente identificados.

Para as estimativas de consumo, a partir da utilização do indicador interno, fibra em detergente ácido (FDAi), foi adotado o procedimento único, sequencial, adaptado às técnicas descritas por Penning e Johnson (1983) e Cochram et al. (1986), com base na digestibilidade in situ, por 144 horas. A estimativa do consumo de matéria seca (CMS) foi realizada empregando-se a equação proposta por Detmann et al. (2001b): CMS (kg/dia) = $\{[($ EFxCIF $)-\mathrm{IS}] / \mathrm{CIFO}\}+\mathrm{CMSS}$, em que CIF = concentração do indicador nas fezes $(\mathrm{kg} / \mathrm{kg})$; $\mathrm{CIFO}=$ concentração do indicador na forragem $(\mathrm{kg} / \mathrm{kg}) ; \mathrm{CMSS}=$ consumo de matéria seca de suplemento $(\mathrm{kg} / \mathrm{dia}) ; \quad \mathrm{EF}=$ excreção fecal (kg/dia); e IS = indicador presente no suplemento (kg/dia). O consumo de MS do pasto foi calculado pela diferença entre o CMS e o CMSS.

A excreção da matéria seca fecal foi estimada utilizando-se o indicador externo óxido crômico, com base na razão entre a quantidade do indicador fornecido e sua concentração nas fezes: matéria seca fecal $(\mathrm{g} / \mathrm{dia})=$ ((quantidade fornecida do indicador - g)/(concentração do indicador nas fezes - \%)) * 100. As determinações de FDN e FDA seguiram os métodos de Van Soest et al. (1991). A quantificação dos carboidratos não fibrosos (CNF) foi feita de acordo com Weiss (1999): $\mathrm{CNF}=\mathrm{CT}-\mathrm{FDNcp}$, em que CT = carboidratos totais (\% MS) e FDNcp = fibra em detergente neutro isenta de cinzas e proteína (\% MS).

A determinação da matéria seca potencialmente digestível (MSpd) foi realizada de acordo com Paulino et al. (2006): MSpd (\%MS) $=\{0,98 \mathrm{x}$ $(100-$ FDN $)\}+($ FDN - FDNi $)$, em que FDN = fibra em detergente neutro $(\% \mathrm{MS})$ e $\mathrm{FDNi}=$ fibra em detergente neutro indigestível (\%MS). As demais análises foram realizadas de acordo com as técnicas descritas por Silva e Queiroz (2002)

As análises referentes aos parâmetros avaliados foram realizadas em delineamento em quadrado latino, sendo que cada animal em um determinado período correspondeu a uma unidade experimental. Para comparação de médias de tratamentos utilizou-se análise de regressão polinomial do programa SAEG (Sistema..., 2002), adotando-se nível de significância de $5 \%$.

\section{RESULTADOS E DISCUSSÃO}

O teor de proteína observado no pasto de Panicum maximum no período da seca, $6,4 \%$, foi próximo ao relatado por Minson (1990), 7,0\%, limitante para a adequada atividade fibrolítica ruminal (Tab. 2). O teor de proteína pode chegar a $4 \%$ ou menos, e isso deve levar à limitação do crescimento microbiano ruminal.

A disponibilidade de MS do pasto foi de 5.168, $4.402,3.970$ e $3.291 \mathrm{~kg} / \mathrm{ha}$ nos períodos $1,2,3 \mathrm{e}$ 4 , respectivamente, com média de $4.207 \mathrm{~kg} / \mathrm{ha}$. Estes valores estão acima de $2.000 \mathrm{~kg}$ de $\mathrm{MS} / \mathrm{ha}$, indicado por Minson (1990) como o limite mínimo para não restringir o consumo em pasto. Dessa forma, a disponibilidade de forragem favoreceu o pastejo seletivo e, consequentemente, a maximização do consumo de matéria seca.

Os consumos de MS, PB, EE e FDN e o teor de NDT apresentaram efeito linear positivo $(\mathrm{P}<0,05)$, em função dos níveis de suplementação, e os consumos de CNF e de pasto não foram influenciados pelos tratamentos (Tab. 3). Portanto, o fornecimento de concentrado promoveu apenas efeito aditivo no consumo de matéria seca com base no estudo de Lange (1980), uma vez que houve acréscimo no consumo de matéria seca total, sem ocorrer efeito sobre o consumo de pasto. De forma similar, Barbosa et al. (2001), ao utilizarem suplementação à base de milho ou farelo de soja, ou ambos os ingredientes simultaneamente, não encontraram diferença significativa para o consumo de forragem em função da suplementação. Este resultado assemelha-se ao de Thiago (2000), segundo o qual, na faixa de amplitude de suplementação de 0,3 a $1,0 \%$ do peso vivo, não ocorreria o efeito substitutivo. Entretanto, para cada $500 \mathrm{~g}$ fornecido acima do estabelecido, ocorreria redução de aproximadamente $300 \mathrm{~g}$ no consumo de forragem com base na MS.

Apesar de o consumo de suplemento ter resultado em efeito aditivo no CMS, este foi baixo quando comparado com o consumo 
esperado, segundo o NRC (Nutrient..., 1996). O baixo CMS talvez possa ser explicado pela qualidade da forragem oferecida (Tab. 2), fato este condizente com os relatos de Mertens (1994), que pressupõe que dietas ricas em fibra podem limitar o consumo por meio do enchimento ruminal. Outra possível causa para o baixo consumo pode ser em relação ao excesso de manipulação a que os animais foram submetidos, como contenção para aplicação de indicador e coleta fecal. Conforme Burns et al. (1994), quanto maior a interferência na rotina de pastejo do animal, menor será o consumo e a excreção fecal.

Em experimento com novilhos, Gomes et al. (2004) observaram CMS de 2,73 kg/animal/dia para o tratamento sem concentrado e de 4,88 e $5,86 \mathrm{~kg} /$ animal/dia para os tratamentos em que os animais receberam 1 e $2 \mathrm{~kg}$ de suplemento/animal/dia. No presente trabalho, os resultados foram semelhantes. Os autores atribuíram o maior CMS dos animais suplementados ao menor teor de FDN e ao maior teor de CNF na dieta.

Tabela 3. Médias do consumo de matéria seca total e consumo de pasto, consumo de nutrientes e teor de nutrientes digestíveis totais na dieta, em função da suplementação; equações de regressão e coeficientes de determinação $\left(\mathrm{r}^{2}\right)$ e de variação $(\mathrm{CV})$ observados em novilhos Nelore, em terminação, na seca

\begin{tabular}{|c|c|c|c|c|c|c|c|}
\hline \multirow{2}{*}{$\begin{array}{l}\text { Item } \\
\text { (kg/animal/dia) }\end{array}$} & \multicolumn{4}{|c|}{ Tratamento (kg/animal/dia) } & \multirow{2}{*}{ Regressão $^{1}$} & \multirow{2}{*}{$r^{2}$} & \multirow{2}{*}{$\mathrm{CV}(\%)$} \\
\hline & 0,0 & 1,0 & 2,0 & 4,0 & & & \\
\hline CMS & 1,83 & 3,31 & 3,45 & 5,71 & $Y=1,95+0,926 * X$ & 0,75 & 23,5 \\
\hline CPasto & 1,83 & 2,64 & 1,97 & 2,15 & - & ns & 37,5 \\
\hline CMS (\%PV) & 0,44 & 0,85 & 0,86 & 1,40 & $Y=0,495+0,224 * X$ & 0,71 & 45,3 \\
\hline СРB & 0,20 & 0,50 & 0,87 & 1,26 & $Y=0,235+0,269 * X$ & 0,86 & 23,6 \\
\hline CEE & 0,037 & 0,075 & 0,073 & 0,287 & $Y=0,007+0,063 * X$ & 0,83 & 38,1 \\
\hline CFDN & 1,31 & 2,19 & 2,10 & 3,54 & $\mathrm{Y}=1,36+0,527 * \mathrm{X}$ & 0,65 & 26,2 \\
\hline $\mathrm{CCNF}$ & 0,23 & 0,53 & 0,34 & 0,50 & - & $\mathrm{ns}$ & 45,7 \\
\hline CNDT & 0,59 & 1,74 & 2,08 & 4,17 & $\mathrm{Y}=0,61+0,872 * \mathrm{X}$ & 0,86 & 26,0 \\
\hline NDT (\%MS) & 31,7 & 52,7 & 58,9 & 74,1 & - & - & - \\
\hline
\end{tabular}

CMS: consumo de matéria seca; CPasto: consumo de matéria seca de pasto; PV: peso vivo; CPB: consumo de proteína bruta; CEE: consumo de extrato etéreo; CFDN: consumo de fibra em detergente neutro; CCNF: consumo de carboidratos não fibrosos; CNDT: consumo de nutrientes digestíveis totais. ${ }^{1} \mathrm{X}$ : suplemento em $\mathrm{kg}$.

Com relação ao consumo de matéria seca em porcentagem do peso vivo (PV), os resultados encontrados também foram baixos, média para todos os tratamentos, excetuando-se o tratamento-controle, de $1,0 \%$ do PV. Valores semelhantes foram observados por Freitas (2004), que, ao trabalhar com suplementação sob pastejo na estação seca do ano, observou CMS da ordem de $1,4 \%$ do PV, também considerado baixo pelo autor.

Estes resultados estão de acordo com o que foi descrito por Moore et al. (1999), que relataram menor impacto na ingestão e na digestibilidade da fibra em alimentos de baixa qualidade, em que há aumento nos teores de carboidratos estruturais. Esses autores relataram que a relação NDT:PB maior que sete é indicativo de baixa qualidade da planta e é provável que haja menor efeito de substituição da ingestão de forragem pelo concentrado.
O consumo de FDN também ficou abaixo do esperado, média de $5,7 \mathrm{~g} / \mathrm{kg}$ de $\mathrm{PV}$, se comparado ao valor de $12,0 \mathrm{~g} / \mathrm{kg}$ de PV de FDN sugerido por Mertens (1992). Este resultado pode ser explicado pelo elevado peso dos animais e pelo excesso de interferência na rotina de pastejo. Ainda, os parâmetros de degradabilidade da FDN de forrageiras tropicais podem ser diferentes dos de forrageiras temperadas (Oliveira et al., 2004).

O aumento linear no consumo (Tab. 3) e na digestibilidade (Tab. 4) de PB, EE e FDN com o fornecimento de concentrado levou ao aumento no CNDT e, com isso, à melhora do desempenho dos animais que consumiam forragens com carências qualitativas. $\mathrm{O}$ consumo crescente de FDN pode ser explicado pelo acréscimo de FDN via suplemento, uma vez que o consumo de pasto não foi alterado pela suplementação. 
Tabela 4. Médias dos coeficientes de digestibilidade da matéria seca e dos nutrientes, em função da suplementação, equações de regressão e coeficientes de determinação $\left(\mathrm{r}^{2}\right)$ e de variação $(\mathrm{CV})$, observados em novilhas Nelore, em terminação, na seca

\begin{tabular}{|c|c|c|c|c|c|c|c|}
\hline \multirow{2}{*}{$\begin{array}{l}\text { Item } \\
(\%)\end{array}$} & \multicolumn{4}{|c|}{ Tratamento (kg/animal/dia) } & \multirow{2}{*}{ Regressão $^{1}$} & \multirow{2}{*}{$\mathrm{r}^{2}$} & \multirow{2}{*}{$\begin{array}{l}\mathrm{CV} \\
(\%)\end{array}$} \\
\hline & 0,0 & 1,0 & 2,0 & 4,0 & & & \\
\hline CDMS & 20,9 & 46,5 & 55,6 & 66,9 & $\mathrm{Y}=28,6+10,7 * \mathrm{X}$ & 0,68 & 24,1 \\
\hline CDPB & 25,6 & 63,2 & 71,7 & 82,3 & $\mathrm{Y}=38,3+12,7 * \mathrm{X}$ & 0,53 & 30,8 \\
\hline CDEE & 7,4 & $-6,7$ & 3,6 & 72,7 & $Y=-12,8+18,2 * X$ & 0,44 & 168,1 \\
\hline CDFDN & 23,8 & 46,0 & 53,8 & 66,7 & $\mathrm{Y}=29,9+10 * \mathrm{X}$ & 0,72 & 20,7 \\
\hline CDCNF & 87,4 & 77,3 & 82,2 & 67,2 & - & ns & 12,4 \\
\hline
\end{tabular}

CDMS: coeficiente de digestibilidade da matéria seca; CDPB: coeficiente de digestibilidade da proteína bruta; CDEE: coeficiente de digestibilidade do extrato etéreo; CDFDN: coeficiente de digestibilidade da fibra em detergente neutro; CDCNF: coeficiente de digestibilidade dos carboidratos não fibrosos. ${ }^{1} \mathrm{X}$ : suplemento em $\mathrm{kg}$.

Cardoso et al. (2000) observaram que o incremento de concentrado resultou em aumento linear nas digestibilidades totais da MS, PB, EE e carboidratos totais, e Costa et al. (2005) verificaram aumento linear para os coeficientes de digestibilidade aparente da MS, EE e CNF. Ladeira (1998) constatou efeito linear apenas sobre a digestibilidade da PB e, de acordo com Dias (1999), o aumento linear nas digestibilidades aparentes da PB e EE pode ser atribuído à menor proporção da fração endógena e ao aumento no consumo desses nutrientes.

O efeito positivo da inclusão de moderada quantidade de alimentos de alta digestão sobre a digestibilidade da fibra é comumente observado com volumosos de menor qualidade (Detmann et al., 2001a). Nesse caso, há estímulo do crescimento microbiano e consequente aumento da degradação da FDN e do consumo de MS (Van Soest, 1994).

No presente trabalho, o $\mathrm{pH}$ ruminal provavelmente manteve-se dentro dos limites fisiológicos em todos os suplementos, pois não houve queda na digestibilidade da fibra. Uma vez que houve aumento da digestibilidade da fibra, pode-se inferir que a adição de concentrado, até a proporção mais elevada de suplementação, propiciou aumento da atividade das bactérias celulolíticas, de forma que estas apresentavam carência nutricional, principalmente de nitrogênio, que, ao ser adicionado à dieta, permitiu um possível aumento da atividade microbiana ruminal. Em níveis mais elevados de suplementação, poderia ser observada alguma inibição da fermentação ruminal, uma vez que as respostas em desempenho passam a ser curvilíneas, segundo Lana (2005b).

\section{CONCLUSÕES}

A suplementação de novilhos em terminação, em pastagens de Panicum maximum cv. Tanzânia, no período de seca, na quantidade de até 4,0kg/animal/dia, estimula o consumo de matéria seca total de forma aditiva, sem afetar o consumo de pasto, melhora a digestibilidade dos nutrientes e, consequentemente, o valor nutritivo da dieta.

\section{AGRADECIMENTOS}

À Integral Nutrição Animal pelo apoio e pela parceria na realização deste trabalho.

\section{REFERÊNCIAS BIBLIOGRÁFICAS}

ADAMS, D.C. Effect of time of supplementation on performance, forage intake and grazing behavior or yearling beef steers grazing Russian wild ryegrass in the fall. J. Anim. Sci., v.61, p.10371042, 1985.

AROEIRA, L.J.M. Estimativas de consumo de gramíneas tropicais. In: SIMPÓSIO INTERNACIONAL DE DIGESTIBILIDADE EM RUMINANTES, 1997, Lavras. Anais.. Lavras: UFLA-FAEPE, 1997. p.127-164.

BARBOSA, N.G.S.; LANA, R.P.; JHAM, G.N. et al. Consumo e fermentação ruminal de proteínas em função de suplementação alimentar energética e proteica em novilhos. Rev. Bras. Zootec., v.30, p.1558-1565, 2001.

BARBOSA, F.A.; GRAÇA, D.S.; MAFFEI, W.E.F. Desempenho e consumo de matéria seca de bovinos sob suplementação proteicoenergética, durante a época de transição água- 
seca. Arq. Bras. Med. Vet. Zootec., v.59, p.160167, 2007.

BURNS, J.C.; POND, K.R.; FISHER, D.S. Measurement of forage intake. In: FAHEY JUNIOR, G.C. (Ed). Forage quality, evaluation and utilization. Madison: America Society of Agronomy, 1994. p.494-531.

CARDOSO, R.C.; VALADARES FILHO, S.C.; COELHO da SILVA, J.F. et al. Consumo e digestibilidades aparentes totais e parciais de rações contendo diferentes níveis de concentrado, em novilhos F1 Limousin x Nelore. Rev. Bras. Zootec., v.29, p.1832-1843, 2000.

COCHRAN, R.C.; ADANS, D.C.; WALLACE, J.D. et al. Predicting digestibility of different diets with internal markers: evaluation of four potential markers. J. Anim. Sci., v.63, p.14761483, 1986.

COSTA, M.A.L.; VALADARES FILHO, S.C.; PAULINO, M.F. et al. Desempenho, digestibilidade e características de carcaça de novilhos zebuínos alimentados com dietas contendo diferentes níveis de concentrado. Rev. Bras. Zootec., v.34, p.268-279, 2005.

DETMANN, E.; PAULINO, M.F.; ZERVOUDAKIS, J.T. et al. Suplementação de novilhos mestiços durante a época das águas: Parâmetros ingestivos e digestivos. Rev. Bras. Zootec., v.30, p.1340-1349, 2001a.

DETMANN, E.; PAULINO, M.F.; ZERVOUDAKIS, J.T. et al. Cromo e indicadores internos na estimação do consumo de novilhos mestiços, suplementados, a pasto. Rev. Bras. Zootec., v.30, p.1600-1609, 2001 b.

DIAS, H.L.C. Consumo, digestibilidades aparentes totais e parciais de dietas contendo diferentes níveis de concentrado, em novilhos F1 Limousin $x$ Nelore. 1999. 76f. Dissertação (Mestrado) - Universidade Federal de Viçosa, Viçosa, MG.

FREITAS, T.B. Recria de novilhos com diferentes níveis de suplementação, na região norte do mato grosso, durante o período da seca. 2004. 48f. Dissertação (Mestrado) Universidade Federal de Viçosa, Viçosa-MG.

GOMES, S.P.; VALADARES FILHO, S.C.; LEÃO, M.I. et al. Consumo e digestibilidade em novilhos alimentados com diferentes dietas. In: REUNIÃO ANUAL DA SOCIEDADE
BRASILEIRA DE ZOOTECNIA, 41., 2004, Campo Grande, MS. Anais... Campo Grande, MS: SBZ, 2004. CD ROM.

LADEIRA, M.M. Consumo e digestibilidades aparentes totais e parciais de dietas contendo diferentes níveis de concentrado, em novilhos Nelore. 1998. 71f. Dissertação (Mestrado) Universidade Federal de Viçosa, Viçosa, MG.

LANA, R.P. Sistema Viçosa de formulação de rações. 3.ed. Viçosa: UFV, 2005a. 91p.

LANA, R.P. Nutrição e alimentação animal (mitos e realidades). Viçosa: UFV, 2005b. 344p.

LANGE, A. Suplementación de pasturas para la producción de carnes. Colección Investigación Aplicada. Rev. Crea, 1980.

McMENIMAN, N.P. Methods of estimating intake of grazing animals. In: SIMPÓSIO SOBRE TÓPICOS ESPECIAIS EM ZOOTECNIA, REUNIÃO ANUAL DA SOCIEDADE BRASILEIRA DE ZOOTECNIA, 34., 1997, Juiz de Fora. Anais... Juiz de Fora, 1997. p.131-168.

MERTENS, D.R. Analysis of fiber in feeds and its use in feed evaluation and ration formulation. In: SIMPÓSIO INTERNACIONAL DE RUMINANTES, REUNIÃO ANNUAL DA SOCIEDADE BRASILEIRA DE ZOOTECNIA, 29., 1992, Lavras. Anais... Lavras: SBZ, 1992. p.1-33.

MERTENS, D.R. Regulation of forage intake. In: FAHEY JR., G.C. (Ed.) Forage quality, evaluation and utilization. Madison: American Society of Agronomy, 1994. p.450-493.

MINSON, D.J. Forage in ruminant nutrition. New York: Academic, 1990. 83p.

MOORE, J.E.; BRANT, M.H.; KUNKLE, W.E. et al. Effects of supplementation on voluntary forage intake, diet digestibility, and animal performance. J. Anim. Sci., v.77, suppl.2, p.122$135,1999$.

NUTRIENT requirements of dairy cattle. 7.ed. Washington, DC: National Academy of Sciences, 1996. 242p.

OLIVEIRA, L.O.F.; SALIBA, E.O.S.; RODRIGUEZ, N.M. et al. Consumo e digestibilidade de novilhos Nelore sob pastagem suplementados com misturas múltiplas. Arq. Bras. Med. Vet. Zootec., v.56, p.61-68, 2004. 

$\begin{array}{llll}\text { PAULINO, } & \text { M.F.; } & \text { DETMANN, E.; } \\ \text { VALADARES } & \text { FILHO, } & \text { S.C. Suplementação }\end{array}$ animal em pasto: Energética ou protéica? In: SIMPÓSIO SOBRE MANEJO ESTRATÉGICO DA PASTAGEM, 3., 2006, Viçosa. Anais... Viçosa, 2006. p.359-392.

PENNING, P.D.; JOHNSON, R.H. The use of internal markers to estimate herbage digestibility and intake. 2. Indigestible acid detergent fiber. $J$. Agric. Sci., v.100, p.133-138, 1983.

SILVA, D.J.; QUEIROZ, A.C. Análise de alimentos: métodos químicos e biológicos. 3.ed. Viçosa: UFV, 2002. 165p.

SISTEMA de análises estatísticas - SAEG. Versão 8.X. Viçosa, MG: UFV, 2002.

THIAGO, L.R.L.S. Suplementação de bovinos a pasto (aspectos práticos para o seu uso na mantença ou ganho de peso) [on-line]. Campo
Grande: Embrapa Gado de Corte, 2000. Disponível em: www.cnpgc.embrapa.br/ publicações/naoseriadas/suplementhiago.

Acessado em: 21 mar. 2000.

VAN SOEST, P.J. Nutritional ecology of the ruminant. 2.ed. Ithaca: Cornell University. 1994. 476p.

VAN SOEST, P.J.; ROBERTSON, J.B.; LEWIS, B.A. Methods for dietary fiber, and nonstarch polysaccharides in relation to animal nutrition. $J$. Dairy Sci., v.74, p.3583-3597, 1991.

WEISS, W.P. Energy prediction equations for ruminant feeds. In: CORNELL NUTRITION CONFERENCE FOR FEED MANUFACTURES, 61., 1999, Ithaca. Proceedings... Ithaca: Cornell University, 1999. p.176-185. 